\title{
Type D personality and metabolic syndrome among Finnish female municipal workers
}

\author{
Susa Majaluoma ${ }^{1,2,3^{*}}$ (D), Tellervo Seppälä ${ }^{1,2,3}$, Hannu Kautiainen ${ }^{4,5,6,7,8}$ and Päivi Korhonen ${ }^{1,2,7,8,9}$
}

\begin{abstract}
Background: Type D personality is a combination of high negative affectivity (NA) and high social inhibition (SI). This personality trait is suspected to impair cardiovascular patients' recovery. The 2016 European Guidelines on cardiovascular disease prevention in clinical practice recommend screening of psychosocial risk factors as Type D personality. The aim of this study was to assess the relationship between Type D personality and Metabolic syndrome (MetS) in working-age female population.

Methods: Six hundred thirty-four female employees with mean age of $48 \pm 10$ years were evaluated. Type D personality and its components (NA) and (SI) were screened with DS14 questionnaire. The definition of MetS was based on measurements done by trained medical staff. We investigated the relationship between Mets and Type D personality, NA and SI using the logistic regression models adjusting for age, education years, leisure-time physical activity, smoking, alcohol use and depressive symptoms.

Results: The prevalence of Type D personality was 10.6\% ( $n=67)$ [95\% Cl: 8.3 to 13.2 ] and MetS $34.7 \%(n=220)$. Type D personality or its subcomponents were not associated with MetS. Women with Type D personality had significantly worse quality of sleep and lower LTPA. They were also more often unsatisfied with their economic situation, they had more often depressive symptoms and psychiatric disorders than non-D type persons. There were no differences in risk factors for cardiovascular diseases.
\end{abstract}

Conclusion: Screening for Type D personality among working- age, reasonably healthy female population seems not to be practical method for finding persons with risk for cardiovascular disease.

Keywords: Type D personality, Metabolic syndrome, Psychosocial risk factors, Women

\section{Background}

Personality traits are suggested to have an impact on the etiology of Metabolic syndrome (MetS), a cluster of cardio metabolic risk factors predisposing to Type 2 diabetes and cardiovascular disease (CVD). To date the results of the studies addressing this issue are inconclusive [1].

\footnotetext{
* Correspondence: susa.majaluoma@porinperusturva.fi

'Institute of Clinical Medicine, Family Medicine, University of Turku and Turku University Hospital University of Turku, 20500 Turku, Finland

2University Hospital, Kiinamyllynkatu 4-8, 20521 Turku, Finland

Full list of author information is available at the end of the article
}

Type D personality is combination of high negative affectivity (NA) and high social inhibition (SI). A person with Type D personality has a tendency to experience negative emotions like worry, irritability, anxiety, and to inhibit self-expression in social situations [2]. Type D personality has been found to be relatively stable over time and independent of mood or health state [2]. The prevalence of this personality type has been estimated to vary $17-38 \%$ in the general population [3, 4] and $26-53 \%$ in cardiac patients [5].

Type D personality has been suspected to impair cardiovascular patients' recovery from cardiac events and to

C C The Author(s). 2020 Open Access This article is licensed under a Creative Commons Attribution 4.0 International License, which permits use, sharing, adaptation, distribution and reproduction in any medium or format, as long as you give appropriate credit to the original author(s) and the source, provide a link to the Creative Commons licence, and indicate if changes were made. The images or other third party material in this article are included in the article's Creative Commons licence, unless indicated otherwise in a credit line to the material. If material is not included in the article's Creative Commons licence and your intended use is not permitted by statutory regulation or exceeds the permitted use, you will need to obtain permission directly from the copyright holder. To view a copy of this licence, visit http://creativecommons.org/licenses/by/4.0/ The Creative Commons Public Domain Dedication waiver (http://creativecommons.org/publicdomain/zero/1.0/) applies to the data made available in this article, unless otherwise stated in a credit line to the data. 
increase their risk of morbidity and mortality [6]. Thus the 2016 European Guidelines on CVD prevention recommend screening of psychosocial risk factors including Type D personality in clinical practice [7]. However it has not been demonstrated that Type D personality predisposes to adverse clinical outcomes in primary prevention setting. There are also gaps in the evidence for CVD prevention in women and young people because they are often underrepresented in clinical trials [7]. The aim of the present study is to assess the relationship between Type D personality and the cluster of CVD risk factors i.e. MetS, in a working-age, reasonably healthy female population. Moreover we aim to assess whether MetS is more or less common in persons with negative affectivity or social inhibition, the subcomponents of Type D personality.

\section{Methods}

\section{Participants}

PORTAAT (Pori To Aid against Threats) is a longitudinal study conducted among employees of the city of Pori (83,500 inhabitants in 2014) in South-Western Finland. The study population was gathered from 10 work units which were selected by the chief of the Welfare Unit of Pori. These work units had not participated in any health promotion program for a few years. The managers of the work units sent an Invitation and study information letters as an email attachment to the employees $(n=2570)$ without exclusion criteria. Information events were also organized for the employees. Altogether 836 employees consented to participate in the study. The gender distribution of the participants (104 men, 732 women) corresponded with the gender distribution of the employees of Pori at the time the study was conducted. The occupations of the participants included librarians, ground keepers, museum employees, computer works, nurses, social workers, physicians, administrative officials and general office staff. The participants were invited to baseline examinations performed by study nurses in the year 2014 .

In the present analysis data from 634 female participants, who attended the PORTAAT-study in 2014 and the follow-up visit in 2015 was reported.

\section{Measures}

Clinical measurements were performed by trained study nurses. Weight and height were measured with the participants in standing position without shoes and outer garments. Weight was measured to the nearest $0.1 \mathrm{~kg}$ with calibrated scales and height to the nearest $0.5 \mathrm{~cm}$ with a wall-mounted stadiometer. Body mass index (BMI) was calculated as weight $(\mathrm{kg})$ divided by the square of height $\left(\mathrm{m}^{2}\right)$.

Waist circumference was measured at the level midway between the lower rib margin and the iliac crest, rounded to the nearest $0.1 \mathrm{~cm}$. The subjects were asked to breathe out gently at the time of measurement, and the tape was held firmly in horizontal position.

Blood pressure was measured with an automatic validated blood pressure monitor after resting at least $5 \mathrm{~min}$ in a sitting position. Two measurements were taken at intervals of at least $2 \mathrm{~min}$ and the mean of these was used in the analysis. The larger cuff was chosen if the arm circumference of the participants was $>32 \mathrm{~cm}$.

Laboratory tests were analyzed from blood samples obtained after at least $8 \mathrm{~h}$ fasting. Plasma glucose, total cholesterol (TC), high-density lipoprotein cholesterol (HDL-C) and triglycerides (TG) were measured enzymatically (Architect c4000/c8000). Low-density lipoprotein cholesterol (LDL-C) was calculated by the Friedewald's formula.

\section{Questionnaires}

The participants completed self-administrated questionnaires at home before the clinical examination.

Type D personality, NA and SI were screened with questionnaire based on DS14 [1]. The DS14 consists of 14 questions; the first 7 questions define NA and the last 7 SI. The answers are chosen on a 5-point Likert scale from 0 to 4 ( 0 = false, $4=$ true). The cut-off scale $>10$ on both NA and SI scales was used to classify participants as Type D, only NA or only SI [1]. The DS14 is a valid instrument with high internal consistency and good testretest reliability [8]. The questionnaire used in this study was the new Finnish version of the DS14 questionnaire, which was produced by the for-ward-backward translation process. Translation from English to Finnish was first performed by four native speakers of Finnish fluent in English. A native English speaker fluent in Finnish and previously unfamiliar with the DS14 translated this Finnish translation back to English. This translation was compared to the original English DS14 for conceptual equivalence.

Metabolic syndrome was defined according to the Harmonization criteria [9] as meeting at least three of the following five criteria:

1) increased waist circumference $\geq 94 \mathrm{~cm}$ for men, $\geq 80 \mathrm{~cm}$ for women

2) elevated blood pressure systolic $\geq 130 \mathrm{mmHg}$ and/or diastolic $\geq 85 \mathrm{mmHg}$ or treatment of hypertension

3) elevated triglycerides $\geq 1.7 \mathrm{mmol} / \mathrm{l}$ or drug treatment for elevated triglycerides

4) reduced HDL cholesterol $<1.0 \mathrm{mmol} / \mathrm{l}$ in men and $<1.3 \mathrm{mmol} / \mathrm{l}$ in women or drug treatment for reduced HDL-C

5) elevated fasting glucose $>5.6 \mathrm{mmol} / \mathrm{l}$ or diagnosed with type 2 diabetes or drug treatment of elevated glucose 
Alcohol consumption was assessed with the three-item Alcohol Use Disorders Identification Test (AUDIT-C) with a cut-off value of 5 for harmful drinking [10].

Smoking status was assessed by a questionnaire. Nonsmoking was defined as having never smoked or have stopped $>12$ months ago.

Leisure-time physical activity (LTPA) was assessed with a questionnaire that evaluated the amount and the intensity of physical activity at leisure time. High LTPA was defined as $\geq 75$ min vigorous intensity activities or $\geq$ 150 min moderate intensity activities or a combination of moderate and vigorous intensity activities per week. Moderate LTPA was defined as 1-149 min moderate or vigorous intensity activities per week and low LTPA if there were no reported moderate or vigorous intensity activities [11].

Table 1 Characteristics of the study subjects

\begin{tabular}{|c|c|c|c|c|c|}
\hline & \multicolumn{4}{|l|}{ DS14 scale } & \multirow[t]{2}{*}{$\boldsymbol{P}$-value } \\
\hline & $\begin{array}{l}\text { None } \\
N=409\end{array}$ & $\begin{array}{l}N A \\
N=65\end{array}$ & $\begin{array}{l}\mathrm{SI} \\
\mathrm{N}=93\end{array}$ & $\begin{array}{l}\text { Type D } \\
N=67\end{array}$ & \\
\hline Age, years, mean (SD) & $48(10)$ & $49(10)$ & $50(9)$ & $49(10)$ & 0.52 \\
\hline Cohabiting, n (\%) & $335(82)$ & $51(78)$ & $74(80)$ & $49(73)$ & 0.39 \\
\hline Education years, mean (SD) & $14(2.6)$ & $13.6(3.0)$ & $14.1(2.7)$ & $14.4(3.0)$ & 0.36 \\
\hline Weight, kg, mean (SD) & $73(14)$ & $72(12)$ & $71(14)$ & $73(15)$ & 0.59 \\
\hline Body mass index, $\mathrm{kg} / \mathrm{m}^{2}$,mean (SD) & $26.9(4.9)$ & $26.8(4.6)$ & $26.6(6.3)$ & $26.5(4.9)$ & 0.91 \\
\hline Waist, cm, mean (SD) & $89(13)$ & $89(13)$ & $88(15)$ & $88(13)$ & 0.73 \\
\hline Audit-C, mean (SD) & $2.8(1.6)$ & $2.8(1.6)$ & $2.6(1.5)$ & $2.9(1.4)$ & 0.62 \\
\hline Smoking, n (\%) & $36(9)$ & $8(12)$ & $7(8)$ & $4(6)$ & 0.60 \\
\hline Good quality of sleep, n (\%) & $318(78)$ & $44(68)$ & $79(85)$ & $42(63)$ & $0.003^{*}$ \\
\hline Major Depression Inventory, mean (SD) & $3.6(4.3)$ & $10.0(7.6)$ & $4.7(3.9)$ & $10.5(7.6)$ & $<0.001^{*}$ \\
\hline Leisure-time physical activity, n (\%) & & & & & $0.018^{*}$ \\
\hline Low & $51(13)$ & $18(28)$ & $12(13)$ & $13(19)$ & \\
\hline Moderate & $192(47)$ & $28(43)$ & $55(59)$ & $31(46)$ & \\
\hline High & $164(40)$ & $19(29)$ & $26(28)$ & $23(34)$ & \\
\hline Financial satisfaction, n (\%) & $309(76)$ & $42(65)$ & $68(73)$ & $40(60)$ & $0.024^{*}$ \\
\hline \multicolumn{6}{|l|}{ Regular medication, n (\%) } \\
\hline Hypertension & $66(16)$ & $9(4)$ & $20(22)$ & $16(24)$ & 0.26 \\
\hline Hypercholesterolemia & $18(4)$ & $2(3)$ & $6(6)$ & $5(7)$ & 0.55 \\
\hline Diabetes & $16(4)$ & $1(2)$ & $3(3)$ & $2(3)$ & 0.92 \\
\hline \multicolumn{6}{|l|}{ Diseases, n (\%) } \\
\hline Musculoskeletal system & $18(4)$ & $5(8)$ & $6(6)$ & $2(3)$ & 0.45 \\
\hline Cardiovascular diseases & $6(1)$ & $1(2)$ & $2(2)$ & $1(1)$ & 0.95 \\
\hline Mental disorders & $2(1)$ & $1(2)$ & $1(1)$ & $4(6)$ & 0.008 \\
\hline Fasting glucose, mmol/L, mean (SD) & $5.49(0.55)$ & $5.43(0.45)$ & $5.52(0.62)$ & $5.56(0.52)$ & 0.46 \\
\hline Fasting lipids, mmol/L, mean (SD) & $5.22(0.91)$ & $5.46(0.92)$ & $5.29(0.86)$ & $5.32(0.99)$ & 0.27 \\
\hline LDL-C & $2.95(0.74)$ & $3.10(0.74)$ & $3.02(0.73)$ & $3.03(0.79)$ & 0.38 \\
\hline $\mathrm{HDL}-\mathrm{C}$ & $1.78(0.45)$ & $1.81(0.45)$ & $1.80(0.43)$ & $1.82(0.43)$ & 0.81 \\
\hline Triglycerides & $1.11(0.58)$ & $1.22(0.68)$ & $1.05(0.52)$ & $1.04(0.40)$ & 0.23 \\
\hline \multicolumn{6}{|l|}{ Blood pressure, mmHg, mean (SD) } \\
\hline Systolic & $131(18)$ & $130(17)$ & $132(17)$ & $130(16)$ & 0.88 \\
\hline Diastolic & $85(11)$ & $85(10)$ & $84(10)$ & $84(10)$ & 0.90 \\
\hline
\end{tabular}

Abbreviations: Audit-C Alcohol Use Disorders Identification Test, LDL-C Low-density lipoprotein cholesterol, HDL-C High-density lipoprotein cholesterol * Hommel's multiple comparison procedure was used to correct significance levels for post hoc testing $(p<0.05)$ :

Good quality of sleep; None/Type D, NA/SI, SI/TYPE D

Major Depression Inventory; None/NA, None/SI, None/Type D, NA/SI, SI/Type D

Leisure time physical activity; None/NA

Financial satisfaction; None/Type D 
Years of education, marital status (cohabiting or not), financial satisfaction (having to spare expenditures or not) were assessed with self-administrated questionnaire. Quality of sleep (very good, good, poor or very poor) was assessed with a single question from Pittsburgh Sleep Quality index [12]. The information about regular medication and diseases diagnosed by a physician was gathered from medical records and with questionnaires. Depressive symptoms were screened with the Major Depression Inventory (MDI) [13].

\section{Statistical analysis}

The data are presented as means with standard deviations (SD) or as counts with percentages. Characteristics of the groups were compared using the analysis of variance (ANOVA) test and chi-square test. In the case of violation of the assumptions (e.g. non-normality), a bootstrap-type test was used. The probability values for pairwise group comparisons were adjusted for multiplicity by use of the Hommel procedure. We investigated the relationship between Mets and DS14 using the logistic regression models, adjusting for age, education years, leisure-time physical activity, smoking, alcohol use, and depressive symptoms. The normality of variables was evaluated using the Shapiro-Wilk W test. Stata 15.1 (StataCorp LP; College Station, Texas, USA) statistical package was used for the analysis.

\section{Results}

Six hundred thirty-four female employees with mean age of $48 \pm 10$ years were evaluated. The prevalence of Type D personality was $10.6 \%(n=67)$ [95\% CI: 8.3 to 13.2 ]. The subcomponent NA was present in $10.3 \%(n=65)$ and SI in $14.7 \%(n=93)$ of the participants. The characteristics of the subjects are presented in Table 1. Women with Type $D$ personality had significantly worse quality of sleep and lower LTPA than women without Type D personality. Type D persons were also more often unsatisfied with their economic situation and they had more often depressive symptoms and psychiatric disorders than non- Type $\mathrm{D}$ persons. There were no differences between the participants in risk factors for cardiovascular diseases.

Figure 1 shows the distribution of NA and Fig. 2 the distribution of SI in the study population and the presence of MetS. The mean of NA score was 5, range 0-23. The mean of SI score was 6, range 0-26.

The prevalence of MetS was 34.7\% $(n=220)$ in our study population. There were no statistical differences between women with or without Type D personality, NA or SI regarding the prevalence of MetS. Neither Type D personality nor NA or SI predicted MetS in multivariate analysis (Table 2 and Fig. 3).

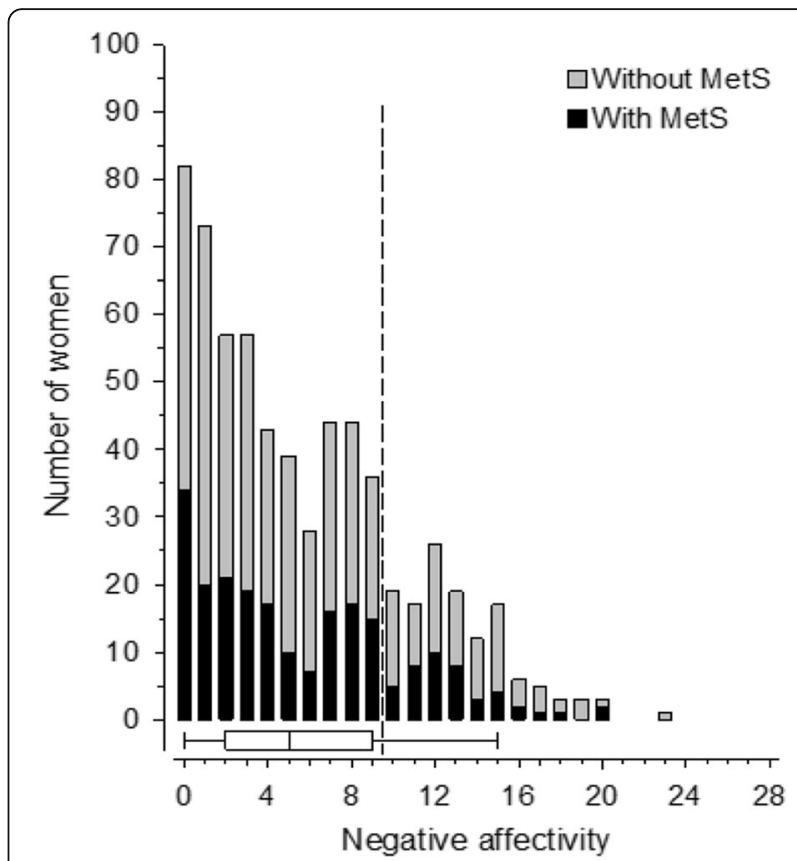

Fig. 1 Distribution of negative affectivity scores in the study population. Box and whiskers plot shows median and interquartile range and whiskers indicate 5th and 95th percentile. Dotted line shows the cut-off score for negative affectivity

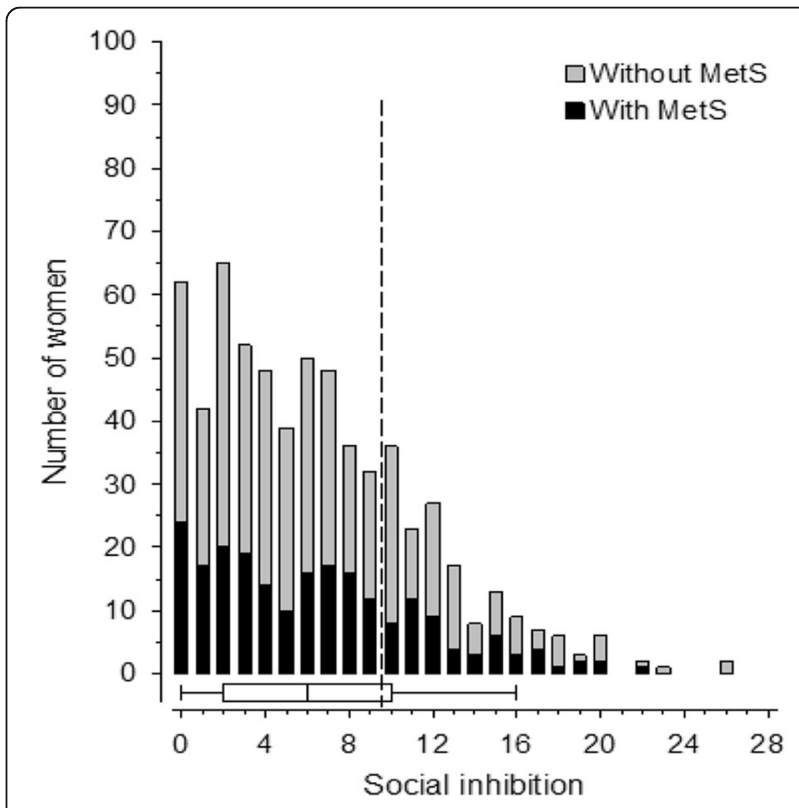

Fig. 2 Distribution of social inhibition scores in the study population. Box and whiskers plot shows median and interquartile range and whisker indicate 5 th and 95 th percentiles. Dotted line shows the cut-off score for social inhibition 
Table 2 Type D personality and its subcomponents as predictors of Metabolic syndrome

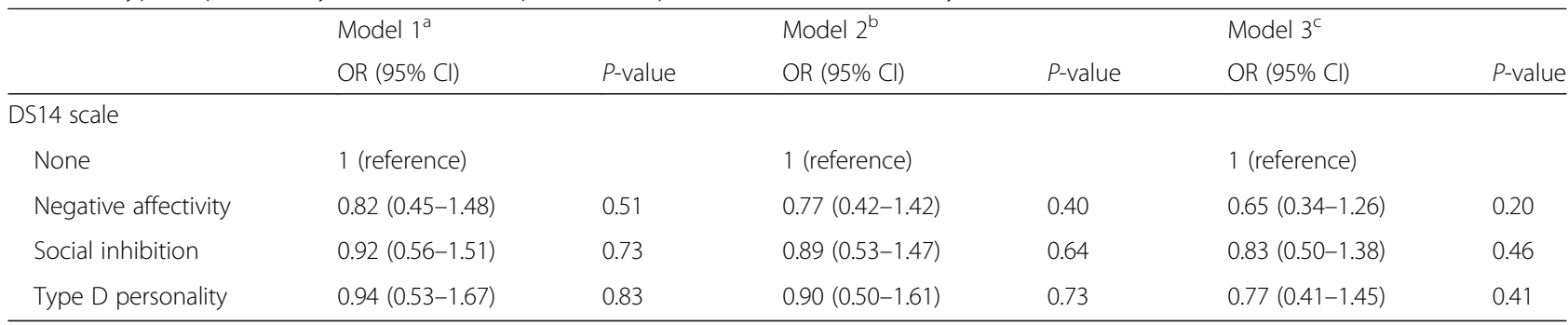

${ }^{a}$ Model 1 adjusted for age and education years

${ }^{\mathrm{b}}$ Model 2 adjusted for age, education years, leisure-time physical activity, smoking and alcohol use

'Model 3 adjusted for age, education years, leisure-time physical activity, smoking, alcohol use and depressive symptoms

\section{Discussion}

The present study indicates that although Type D personality and MetS are quite common in working- age women, there is no association with Type D personality or its subcomponents and MetS. Instead participants with Type D personality slept worse, reported LTPA, had more depressive symptoms and were more dissatisfied with their financial situation than subjects without Type D personality. The negative way of thinking and cynicism might at least partly explain these differences. In our study population, one out of 10 women had Type $\mathrm{D}$ personality and about a third of the participants had MetS. The prevalence of Type D is relatively low in the study population, but to our knowledge, this is the first study assessing Type D personality in Finland.

There are few studies concerning Mets and Type D personality.
In the Netherlands, Mommersteeg et al. detected a twofold increased risk of having Mets in persons with Type D personality [14]. The study population was 1592 participants from general population aged $20-80$ years. Mets was defined by self-report and the prevalence of MetS was 7.3\%.

In Greece, Tziallas et al. also found an association between Type D personality and MetS [15]. The study population consisted of 359 patients of an outpatient lipid clinic in a University Hospital. In this highly selected population the prevalence of Mets was 57.4\%.

Findings in the present study are similar with a German study among 458 workers ( $80 \%$ men) of an airplane manufacturing company [16]. The prevalence of Type D personality was $32 \%$ (30\% in men, $38 \%$ in women) and the prevalence of Mets 14\%. Type D personality, NA or SI were related to Mets neither in cross-sectional nor longitudinal (mean follow-up time 6.3 years) research frame [16].
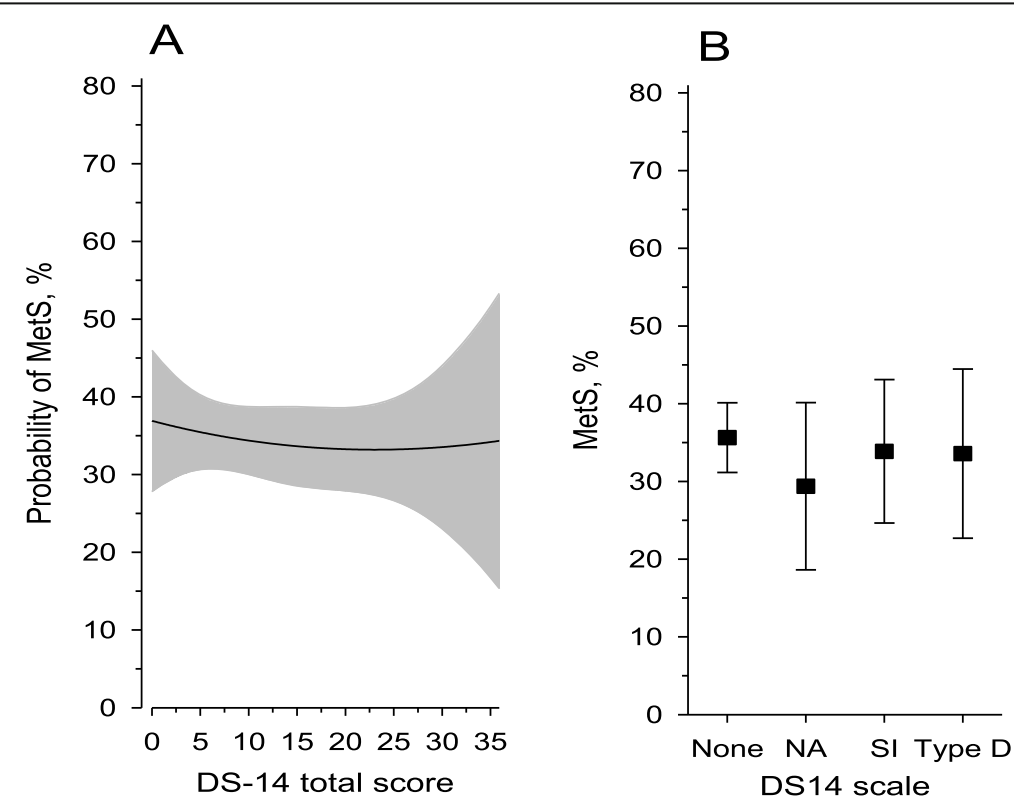

Fig. 3 a Estimated probability of Metabolic syndrome according to the DS-14 total score. The curve was derived from logistic regression model. The $95 \%$ confidence intervals are denoted by gray areas. b Occurrence of metabolic syndrome according Type D personality and its components. Values were adjusted for age, leisure-time physical activity and education years 
The major limitation of our study is its cross-sectional nature and thus any causal relationship between Type D personality and MetS cannot be done. Although no association between Type D personality and Mets was found, the situation might be different in 5-10years. Selfreporting of diet, physical activity and smoking status may also be unreliable, but we use validated questionnaires and standardized procedures in order to overcome this bias. We excluded male employees because there were so few of them and thus the results and interpretations cannot be generalized to men. However the mean age and gender distribution among the PORTAAT study participants resemble the distribution of all employees of the city of Pori and also Finnish public sector employees overall [17]. The mean annual rate of sickness absence days among the study participants was comparable to the non-participants in the included employment sectors [18]. The response rate of $32.5 \%$ is relatively low, but it is known that E-mail surveys generally have about $20 \%$ lower response rate than mail surveys [19]. It is also possible that person with Type $\mathrm{D}$ personality are reluctant to attend this kind of survey indicating lifestyle related factors. People with better health are more likely to attend health surveys and thus the healthy worker effect is possible in our study. The prevalence of psychiatric disorders is low (1.3\%) in this study population of active work force. Even though previously detected diseases were assessed both through register data and by clinical interview, there is a possibility that psychiatric disorders were underdiagnosed. The strength of our study is that the clinical measurements were done by trained medical staff and consensus definition of MetS was used. Also many aspects of health related behaviors was taken into account.

\section{Conclusion}

Screening for Type D personality in working-age, relatively healthy female population seems not to be practical method for finding persons at risk for CVD or Type 2 diabetes. Although we found no association between Type D personality and MetS, the subcomponent negative affectivity may be related to depressive symptoms and sleep disorders among female employees. This finding warrants for further investigations about the impact of Type D personality on individuals' mental health and quality of life.

\section{Abbreviations}

CVD: Cardiovascular disease; NA: Negative affectivity; SI: High social inhibition; MetS: Metabolic syndrome; LTPA: Leisure time physical activity; BMI: Body mass index; TC: Total cholesterol; HDL-C: High-density lipoprotein cholesterol; TG: Triglycerides; LDL-C: Low-density lipoprotein cholesterol; AUDIT-C: Alcohol Use Disorders Identification Test; MDI: The Major Depression Inventory

Acknowledgements Not applicable.

\section{Authors' contributions}

SM, TS and PK contributed to conception and design of the manuscript. SM, TS, HK, PK analyzed and interpreted the data. SM, HK and PK drafted the manuscript. SM, TS, HK, PK critically revised the manuscript. All authors read and approved the final manuscript.

\section{Funding}

This research received no specific grant from any funding agency in the public, commercial or not-for profit sectors.

\section{Availability of data and materials}

The datasets during and/or analyzed during the current study available from the corresponding author on reasonable request.

\section{Ethics approval and consent to participate}

The study protocol and consent forms were reviewed and approved by ethics committee of the Hospital District of Southwest Finland, Turku

Finland. All participants provided written informed consent for project and subsequent medical research. Administrative permissions to access the raw data from PORTAAT (Pori To Aid against Threats) Study were not required because the principal investigator, professor Päivi Korhonen belongs to our research team.

\section{Consent for publication}

Not applicable.

\section{Competing interests}

The authors declare that they have no competing interests.

\section{Author details}

${ }^{1}$ Institute of Clinical Medicine, Family Medicine, University of Turku and Turku University Hospital University of Turku, 20500 Turku, Finland. ${ }^{2}$ University Hospital, Kiinamyllynkatu 4-8, 20521 Turku, Finland. ${ }^{3}$ Health Center of Pori, Siltapuistokatu 2, 28100 Pori, Finland. ${ }^{4}$ Department of General practice and Primary Health Care, University of Helsinki and Helsinki University Hospital, University of Helsinki, Yliopistonkatu 4, 00100 Helsinki, Finland. ${ }^{5}$ Helsinki University Hospital, Helsingin ja Uudenmaan sairaanhoitopiiri, Stenbäckinkatu 9, PL 100, 00029 HUS Helsinki, Finland. ${ }^{6}$ Folkhälsan Research Center, Haartmaninkatu 8, 00290 Helsinki, Finland. Unit of Primary Health Care, University of Kuopio, University Hospital Kuopio. University of Kuopio, Yliopistonranta 1, 70210 Kuopio, Finland. ${ }^{8}$ University Hospital of Kuopio, Puijonlaaksontie 2, 70210 Kuopio, Finland. ${ }^{9}$ Central Satakunta Health Federation of Municipalities, Koulukatu 2, 29200 Harjavalta, Finland.

Received: 18 November 2019 Accepted: 18 August 2020

Published online: 14 September 2020

\section{References}

1. Mommersteeg PM, Pouwer F. Personality as risk factor for the metabolic syndrome: a systematic review. J Psychosom Res. 2012;73:326-33.

2. Denollet J. DS 14: standard assesment of negative affectivity, social inhibition, and type D personality. Psychosom Med. 2005;67:89-97.

3. Mols F, Denollet J. Type D personality in the general population: a systematic review of health status, mechanisms of disease, and work-related problems. Health Qual Life Outcomes. 2010;9:9.

4. Hausteiner C, Klupsch D, Emeny R, Baumert J, Ladwig KH. Clustering of negative affectivity and social inhibition in the community: prevalence of type D personality as a cardiovascular risk marker. Psychosom Med. 2010;72: 163-71.

5. Kupper N, Denollet J. Type D personality as a prognostic factor in heart disease: assessment and mediating mechanisms. J Pers Assess. 2007;89:26576.

6. Denollet J, Sys SU, Stroobant N, Rombouts H, Gillebert TC, Brutsaert DL. Personality an independent predictor of long -term mortality in patients with coronary heart disease. Lancet. 1996;34:417-21.

7. Piepoli MF, Hoes AW, Agewall S, et al. 2016 European guidelines on cardiovascular disease prevention in clinical practice. The sixth joint task force of the European Society of Cardiology and Other Societies on cardiovascular disease prevention in clinical practice. Eur Heart J. 2016;37: 2315-81. 
8. Whitehead DL, Perkins-Porras L, Strike PC, Magid K, Steptoe A. Cortisol awakening response is elevated in acute coronary syndrome patients with type- D personality. J Psychosom Res. 2007;62:419-25.

9. Alberti KG, Eckel RH, Grundy SM, et al. Harmonizing the metabolic syndrome: A joint interim statement of international diabetes federation task force on epidemiology and prevention; national heart, lung and blood institute; American heart association; World heart federation; International atherosclerosis society; and international association for study of obesity. Circulation. 2009;120:1640-50.

10. Bush K, Kivlahan DR, McDonell MB, Fihn SD, Bradley KA. The AUDIT alcohol consumption questions (AUDIT-C): an effective brief screening test for problem drinking. Ambulatory care quality improvement project (ACQUIP). Alcohol use disorders identification test. Arch Inter Med. 1998;158:1789-95.

11. Lloyd-Jones DM, Hong Y, Labarthe D, et al. Defining and setting national goals for cardiovascular health promotion and disease reduction: the American Heart Association's strategic impact goal through 2020 and beyond. Circulation. 2010;121:586-613.

12. Marques DR, Meia-Via AMS, da Silva CF, Gomes AA. Associations between sleep quality and domains of quality of life in non-clinical sample: results from higher education students. Sleep Health. 2017;3(5):348-56.

13. Bech P, Rasmussen NA, Olsen LR, Noerholm V, Abildgaard W. The sensitivity and specificity of the major depression inventory, using the present state examination as the index of diagnostic validity. J Affect Disord. 2001;66(2-3): 159-64.

14. Mommersteeg PM, Kupper N, Denollet J. Type D personality is associated with increased metabolic syndrome prevalence and an unhealthy lifestyle in a cross-sectional Dutch community sample. BMC Public Health. 2010;10:714.

15. Tziallas D, Kostapanos MS, Skapinakis $P$, et al. The association between type $D$ personality and the metabolic syndrome: a cross-sectional study in a university-based outpatient lipid clinic. Short Report. BMC Res Notes. 2011;4: 105.

16. Mommersteeg PM, Herr R, Bosch J, Fischer JE, Loerbroks A. Type D personality and metabolic syndrome in a 7-year prospective occupational cohort. J Psychosom Res. 2011;71:357-63.

17. Kouvonen A, Kivimäki M, Väänänen $A$, et al. Job strain and adverse health behaviors: the Finnish public sector study. J Occup Environ Med. 2007;49: 68-74.

18. Vuorio $\mathrm{T}$, Suominen $\mathrm{S}$, Kautiainen $\mathrm{H}$, et al. Determinants of sickness absence rate among Finnish municipal employees. Scand J Prim Health Care. 2019; 37:3-9.

19. Shih T, Fan X. Comparing response rates in e-mail and paper surveys: a meta-analysis. Ed Res Rev. 2009;4(1):26-40.

\section{Publisher's Note}

Springer Nature remains neutral with regard to jurisdictional claims in published maps and institutional affiliations.

Ready to submit your research? Choose BMC and benefit from:

- fast, convenient online submission

- thorough peer review by experienced researchers in your field

- rapid publication on acceptance

- support for research data, including large and complex data types

- gold Open Access which fosters wider collaboration and increased citations

- maximum visibility for your research: over $100 \mathrm{M}$ website views per year

At $\mathrm{BMC}$, research is always in progress.

Learn more biomedcentral.com/submissions 